\title{
DETC2018-86166
}

\section{DRAFT: ADAPTING THE FBS MODEL OF DESIGNING FOR USAGE-DRIVEN INNOVATION PROCESSES}

\author{
Bernard Yannou \\ Laboratoire Genie Industriel, CentraleSupélec, \\ Université Paris-Saclay \\ Gif-sur-Yvette, France
}

\author{
François Cluzel \\ Laboratoire Genie Industriel, CentraleSupélec, \\ Université Paris-Saclay \\ Gif-sur-Yvette, France
}

\author{
Guillaume Lamé \\ THIS Institute (The Healthcare Improvement Studies Institute), \\ University of Cambridge \\ Cambridge, Cambridgeshire, United Kingdom
}

\begin{abstract}
There has been rising interest in confronting formal models of design with practical design methods, in order to understand better both and to explore how they can improve each other. In this article, we try to map the Radical Innovation Design (RID) methodology in Gero's Function-Behavior-Structure (FBS) framework. We encounter difficulties in doing so, and propose new constructs extending the FBS framework to account for some processes in RID. For instance, FBS is extended to describe the early stages of RID, where usages are analyzed to identify the appropriate situations and problems on which to innovate. We present a short practical case study to illustrate the relevance of these concepts. Our findings join those of others who have investigated the use of FBS to illustrate innovative projects, where requirements are unclear. We propose perspectives for future research, notably pursuing this work with the situated FBS framework.
\end{abstract}

\section{INTRODUCTION}

The lack of validation of design methods is sometimes lamented [1]. Analyzing design methods through the lens of design theories is one way forward to understand the mechanisms through which they support good design practice and promote value creation. Using theories to understand and assess methods, treatments and programs is a long-standing proposition in evaluation research [2]. In return, confronting design theories with design methods that have positive practical impact could be one way of testing them.

This article is part of a research program aimed at exploring how our understanding of the Radical Innovation Design (RID) methodology [3-6] can be enhanced by confronting it with existing formal frameworks of design reasoning and of design process. We have already looked at RID through the lens of abductive design and the two-step innovative abduction model [7]. The study showed how RID differs from this general model of design reasoning, because of RID's emphasis on mapping usages and structured approach to identifying the right end-user problems and usage situations to tackle [8]. We want to continue this work by using other lenses to analyze RID, starting with Gero's Function-Behavior-Structure (FBS) framework [9]. Since it was first proposed by Gero, FBS has generated regular debate on its nature, role and comprehensiveness [10-13]. In this first article on RID and FBS, we limit ourselves to the traditional FBS framework, without including the more recent situated FBS [11].

In the next section, we introduce the RID methodology. We then present the FBS framework. We try to map RID in the FBS framework, identify the difficulties in doing so and propose new constructs that seem appropriate to better describe usage-driven innovation processes. A case study is presented to illustrate these constructs. We discuss these findings in light of the theoretical debates on FBS, and propose areas for further investigation.

\section{THE RADICAL INNOVATION DESIGN METHODOLOGY}

\section{Principles}

The Radical Innovation Design (RID) methodology was developed and refined over the past decade. It was developed in close interaction with design practice, through experiments carried in industrial $\mathrm{PhDs}$, in engineering education or in professional development courses.

A core principle of the RID methodology is the concept of usage. RID initially started from the principle that it is what you want to do that counts when choosing a product, not who you are. In 
other terms, RID postulates that intended usage is more

important than users' personal characteristics (e.g., age, gender)

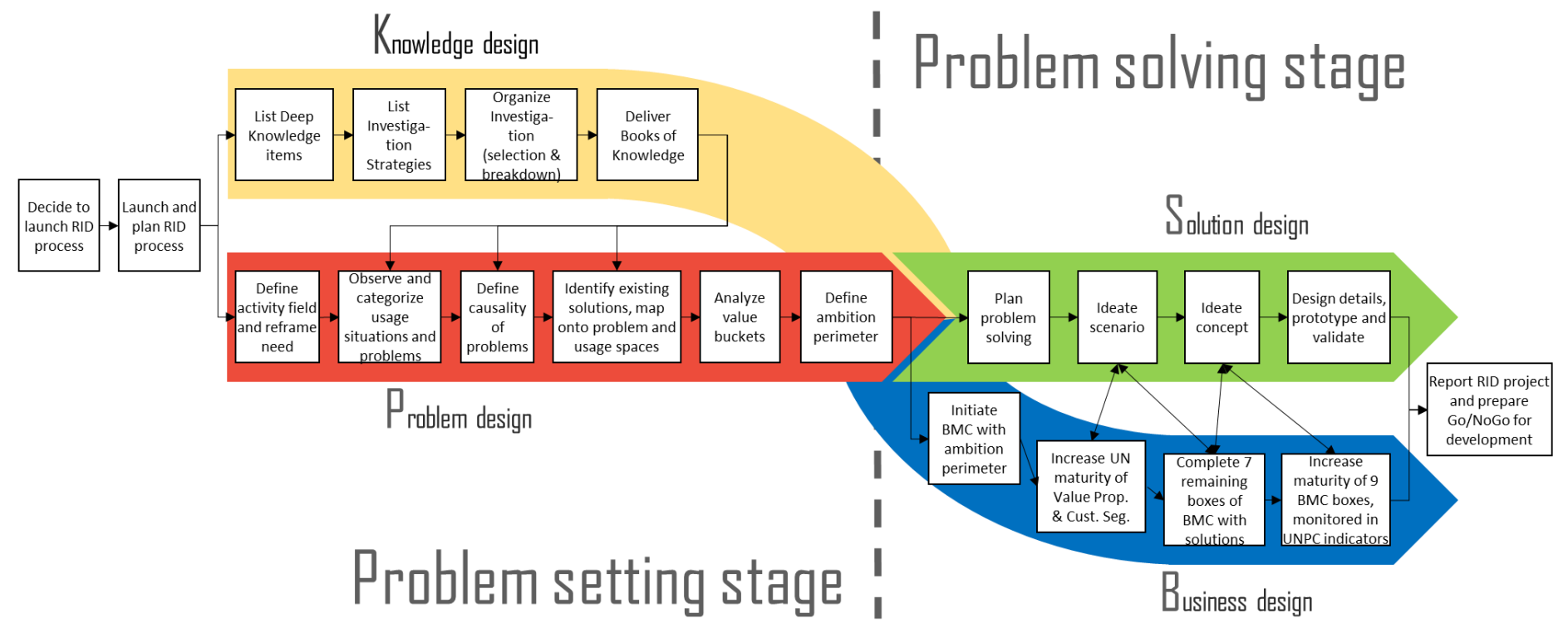

\section{FIGURE 1. THE RID PROCESS (BMC: BUSINESS MODEL CANVAS, UN: USEFULNESS-NOVELTY, UNPC: USEFULNESS- NOVELTY-PROFITABILITY-CONCEPT)}

when choosing a product, and that understanding and modelling usages could help identifying successful concepts and products [14]. This approach was also used to simulate the performance of existing products to solve a given issue [15].

By putting emphasis on usage, RID acknowledges that a new product or service will necessarily need to become part of a complex system of practices. In this context, one can rarely identify clear-cut requirements from which to design a system, particularly in the case of radical innovations. This situation mandates an investigation of what people do, what issues they encounter, and how existing artefacts address these problems. To do so, RID structures and supports in-depth analysis of usages, problems and performance of existing solutions, supported by modelling [3].

This approach is very consistent with established principles in innovation management, such as Christensen's "jobs-to-bedone" concept [16], which extends the usual notion of function to focus on user-centered considerations; the creation of "blue oceans", where innovators invest in untapped market spaces by providing solutions to problems that have not yet been identified by competitors or to users who have not been addressed by the current market [17]; and need-seeker innovation, a type of innovation driven by usages rather than technologies [18].

The emphasis on problem setting in RID has proven its benefits, since it was shown that the quality of the problem setting stage affected positively the final design results [4]. Readers interested in practical examples and the application of RID to industrial problems may be referred to $[3,19,20]$.

\section{The Process of RID}

Figure 1 illustrates the process of RID. RID is split into two stages and four sub-processes: The Problem setting stage, with the knowledge design and problem design sub-processes, and the Problem solving stage, with the solution design and businessdesign sub-processes.

In the Problem setting stage, designers start by defining an activity field in which it is suspected that something can be done to create value. This activity field is investigated empirically to identify archetypal usage situations and problems met by users. Designers model how problems happen through causal modelling. They also investigate how existing solutions act on these causal networks, and how they ultimately alleviate users' problems. This information is then processed using an algorithm, which helps identify the frequent usage situations where serious problems happen which are not well addressed by existing solutions [3]. These instances are called "value buckets". To identify the ones that are worth exploring further, a Kano survey is carried with potential users, and the fitness between value buckets and the company's strategy is also taken into account. In the end, a subset of value buckets is selected for further investigation, called the ambition perimeter.

This Problem design sub-process is supported by intensive research to create a knowledge base, the Knowledge design subprocess. Designers use empirical research approaches (participant observation, interviews), literature review and expert opinions to construct "books of knowledge" on relevant topics.

In the Problem solving stage, designers concurrently develop a solution system (Solution design) and its business 
model (Business design). The Solution design process starts by the definition of ambitioned usage scenarios, where the solution is not represented but its desired effects are illustrated in narrative form. Based on this, designers ideate on concepts that could deliver the ambitioned usage scenarios. They then proceed to a more classical systems design, where the system is progressively refined.

In parallel, the business model of the system is investigated through the progressive refinement of a Business Model Canvas [21]. The business value of the system is monitored through a set of indicators on Usefulness, Novelty, Profitability and Concept soundness [22].

Now that we have described the RID methodology, we propose in the next section a description of the FBS (FunctionBehavior-Structure) conceptual framework, of its evolutions and applications.

\section{THE FBS MODEL OF DESIGNING}

John Gero introduced the FBS (Function-BehaviorStructure) model of designing in a seminal paper published in 1990 [9]. This model has then evolved with the contribution of Gero and his colleagues as well as other researchers from the Design Science community. The FBS framework is nowadays considered as a 'reference model to describe the design processes and tasks' [12], even if some ambiguities and weaknesses have been revealed over the years $[10,12,13]$. We first give a general overview of the model, and then we highlight the main criticisms found in the literature, before showing some applications.

\section{Overview of the FBS framework}

TABLE 1. DEFINITION OF THE SIX DESIGN ISSUES [23]

\begin{tabular}{ll}
\hline Design Issue & Definition \\
\hline $\begin{array}{l}\text { Requirements } \\
\text { (R) }\end{array}$ & $\begin{array}{l}\text { All expressions of customer or market } \\
\text { needs, demands, wishes and constraints that } \\
\text { are explicitly provided to the designers at } \\
\text { the outset of a design task }\end{array}$ \\
\hline Function (F) & $\begin{array}{l}\text { Teleological representations that can cover } \\
\text { any expression related to potential purposes } \\
\text { of the artefact }\end{array}$ \\
\hline $\begin{array}{l}\text { Expected } \\
\text { Behavior (Be) }\end{array}$ & $\begin{array}{l}\text { Attributes that describe the artefact's } \\
\text { expected interaction with the environment }\end{array}$ \\
\hline $\begin{array}{l}\text { Structure } \\
\text { Behavior (Bs) }\end{array}$ & $\begin{array}{l}\text { (or behavior derived from structure) } \\
\text { calculated or derived from the observation } \\
\text { of a specific design solution and its } \\
\text { interaction with the environment }\end{array}$ \\
\hline Structure (S) & $\begin{array}{l}\text { Components of an artefact and their } \\
\text { relationships }\end{array}$ \\
\hline $\begin{array}{l}\text { Design } \\
\text { description } \\
\text { (D) }\end{array}$ & $\begin{array}{l}\text { Any form of design-related representations } \\
\text { produced by designers, at any stage of the } \\
\text { design process }\end{array}$ \\
\hline
\end{tabular}

The FBS conceptual framework [12, 23], or model of designing $[10,13]$ - both terms are invariably used in this paper -, or even design ontology [24] has been first introduced by John Gero in 1990 as a representation schema to support 'the initiation and continuation of the act of designing' [9]. It has then been described and improved in a series of scientific papers by Gero and colleagues, and with contributions from other researchers (see next subsection).

A consolidated version of the FBS framework is presented in this section, i.e. the most commonly used version in the past years, for example in [23]. Figure 2 illustrates this framework. The FBS model describes the act of designing with six design issues and eight fundamental processes linking these design issues in a generic design process. Table 1 gives a definition of the six design issues.

The FBS model expressed that designing an artefact aims at transforming a set of requirements and functions into a set of design descriptions [24]. In the FBS model, this process is broken down into eight fundamental design processes, described in Table 2 and numbered on Figure 2.

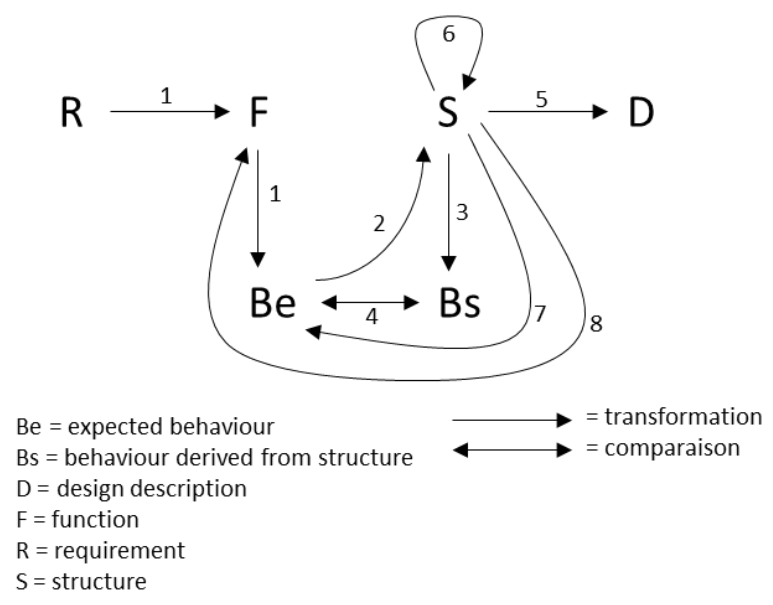

FIGURE 2. THE FBS MODEL MADE OF SIX DESIGN ISSUES AND EIGHT FUNDAMENTAL PROCESSES

TABLE 2. THE EIGHT FUNDAMENTAL DESIGN PROCESSES SYNTHETIZED FROM KANNENGIESSER AND GERO [23]

\begin{tabular}{ll}
\hline Fundamental process & Description \\
\hline Formulation (1) & $\begin{array}{l}\text { Transforms requirements into } \\
\text { functions }(\mathrm{R} \rightarrow \mathrm{F}) \text { and functions } \\
\text { into expected behavior }(\mathrm{F} \rightarrow \mathrm{Be})\end{array}$ \\
\hline Synthesis (2) & $\begin{array}{l}\text { Transforms expected behavior into } \\
\text { structure }(\mathrm{Be} \rightarrow \mathrm{S})\end{array}$ \\
\hline Analysis (3) & $\begin{array}{l}\text { Transforms structure into structure } \\
\text { behavior }(\mathrm{S} \rightarrow \mathrm{Bs})\end{array}$ \\
\hline Evaluation (4) & $\begin{array}{l}\text { Compares expected behavior with } \\
\text { structure behavior }(\mathrm{Be} \leftrightarrow \mathrm{Bs})\end{array}$ \\
\hline Documentation (5) & $\begin{array}{l}\text { Transforms structure into a } \\
\text { description }(\mathrm{S} \rightarrow \mathrm{D})\end{array}$ \\
\hline
\end{tabular}




\begin{tabular}{|c|c|}
\hline $\begin{array}{l}\text { Reformulation type } 1 \\
\text { (6) }\end{array}$ & $\begin{array}{l}\text { Transforms structure into new } \\
\text { structure }\left(S \rightarrow S^{\prime}\right)\end{array}$ \\
\hline $\begin{array}{l}\text { Reformulation type } 2 \\
\text { (7) }\end{array}$ & $\begin{array}{l}\text { Transforms structure into new } \\
\text { expected behavior }(\mathrm{S} \rightarrow \mathrm{Be} \text { ') }\end{array}$ \\
\hline $\begin{array}{l}\text { Reformulation type } 3 \\
\text { (8) }\end{array}$ & $\begin{array}{l}\text { Transforms structure into } \\
\text { function }\left(\mathrm{S} \rightarrow \mathrm{F}^{\prime} \text { via } \mathrm{Be}\right)\end{array}$ \\
\hline
\end{tabular}

A useful (in the context of this paper) complement is provided in [24], where the design issues and the fundamental processes are classified in terms of problem or solution space:

- Reasoning about problem includes requirements (R), function (F) and expected behavior (Be), as well as formulation (1), reformulation type 2 (7) and reformulation type 3 (8);

- Reasoning about solution includes behavior from structure (Bs), structure (S) as well as synthesis (2), analysis (3), evaluation (4) and reformulation type 1 (6).

The main evolution of the FBS model proposed by Gero and colleagues themselves is called the situated FBS (sFBS) framework. This evolution has been proposed to answer to one of the main criticism of the FBS framework, namely the lack of 'the dynamic character of the context in which designing takes place. [...] Many agent-based systems are based on traditional models and theories of designing that assume the world as being fixed, well-defined and unchanged by what you do' [11]. In this dynamic framework, the design issues and fundamental processes are instantiated in three worlds:

- The external world includes representations outside the designer;

- $\quad$ The interpreted world is built up inside the designer. It represents the interpreted representation of the external world by the designer;

- The expected world is predicted by the interpretation of the designer.

The sFBS framework is not described in more details in this paper, as the analysis is performed with the 'classical' FBS framework. It is however evoked as one on the main perspective of extension of this work in the discussion section.

\section{Discussions of the FBS framework}

The FBS model of designing has been largely discussed in the literature. Three major contributions lie in successive publications in Design studies journal.

Vermaas \& Dorst [13] recognize the high value of the FBS model, but they identify two problems: the absence of a stable definition of function, and the ambiguity of the model to be at the same time descriptive and prescriptive. The first problem, the definition of a function, is a recurrent issue in design methodologies. These functions are assumed to be originated from clients, but function's definition has changed over time in the FBS framework, which leads also to different descriptions of the first fundamental process (Formulation). In the literature, 'designing starts with a client's intentional aim or desire, and produces a physicochemical description of an artefact by which the client can make the aim or desire come true' [13]. They highlight the lack of 'use' consideration in FBS, which is the way artefacts are used (purpose of the artefact) and is distinct from the notion of function. They propose to distinguish between function and purpose.

Galle [10] goes a bit further by discussing the evolutions proposed by Vermaas \& Dorst [13]. He mainly highlights the fact that FBS referred to an artefact under design, 'at which time, however, the artefact in question could not yet have been available' [10]. Even if implications are different, this problem may be encompassed in a broader issue dealing with the lack of dynamics of the FBS framework, including also the descriptive/prescriptive discussion from Vermaas and Dorst [13] and the introduction of the sFBS [23].

A last remarkable discussion about FBS is proposed by Cascini et al. [12] about, one more time, the first process (formulation) and design issues (Requirements and Function). They propose an evolution of the situated FBS framework by making a distinction between Needs (N, a new design issue) and Requirements (R) and by instantiating these objects in the three situated worlds. We do not discuss in detail these proposals in this paper, but one remarkable observation is the introduction of considerations that go beyond the design of material objects (in a mechanical design tradition). Indeed, they introduce marketing literature and vocabulary with concepts such as utility to the customer, value provided to the customer, user-centric design, customer behavior or usage contexts. They highlight the difficulty to attain customer's needs 'due to the problem of inadequate requirement definition' [12]. They mention design problems like 'functional fixedness' or in 'picturing the average customer', and they consider the traditional way to express requirements in design as too simplistic. Their adaptation of the sFBS model aims at supporting 'a more careful and detailed investigation of the processes that occur in the earlier stages of design' [12]. Needs is defined as 'an expression of a perceived undesirable situation to be avoided of a desirable situation to be attained'. Needs may be explicit (expressed to the designer) or tacit (observed by the designer from users' behavior), and Requirements become 'a measurable property related to one or more Needs' [12].

\section{Applications of the FBS framework}

The FBS model of designing has been applied to different contexts with different purposes. One may distinguish two main fields of application, 'as a theoretical vehicle for understanding design, and as a conceptual basis for computerized tools intended to support practicing designers' [10]. Let us illustrate four recent applications.

Pourmohamadi and Gero [25] use FBS as a coding scheme to structure a software tool, LINKOgrapher, which aims at automating the calculations in design protocol analysis. FBS coding scheme ensures a domain-independent re-usability of the tool to assist designers.

Lammi [26] considers FBS to analyze high school students' system thinking in engineering design. FBS design issues are used to support the analysis of students' reasoning (mental 
issues, activities and operations) when facing a design challenge, and then to identify common or recursive cognitive schemes that could inspire learning paths.

In another study, the 40 inventive principles of TRIZ are analyzed thanks to the FBS model [27]. In most of the cases, the TRIZ principles match the FBS model, but for some principles, their definition is improved to act on the function, the behavior and the structure of the system.

Finally, Gero et al. [24] propose to compare design cognition while using different concept generation creativity techniques such as brainstorming (unstructured technique), morphological analysis (partially structured technique) and TRIZ (structured technique). The results show that how structured the technique is directly influences the ability of the users to focus on problemrelated aspects of designing.

These different applications show the ability of the FBS model of designing to analyze design and innovation methodologies and software in terms of design cognition and efficiency. Moreover, the previous subsections show also some questioning on the notion of function and the integration of users' need $[12,13]$. These issues are central in the philosophy, principles and process of RID. Therefore, we propose in the next sections to investigate how RID can fit in the FBS framework, and how this framework can be adapted to better consider cognitive processes of usage-driven innovation methodologies like RID.

\section{METHOD}

The current study has been performed following these steps:

1. Mapping of the RID process in the FBS framework

2. Identification of questionable FBS design issues and processes in a usage-driven innovation context

3. Proposal of new design issues and processes to complement the FBS model

4. Illustration of the adapted model on a successful RID student project

The FBS framework considered in this study is the one used in [23], i.e. the 'classical' FBS framework. We do not consider in this paper the evolutions proposed in other studies, such as that by Cascini et al. [12] or the situated FBS model [11], as this study is a first attempt to project RID methodology in the FBS framework. Future work will confront the RID methodology to FBS evolutions. Results are presented in the next section.

\section{RESULTS}

By trying to explain the RID process with the FBS model, several weaknesses or ambiguities have rapidly been identified with the two first design issues (Requirements and Functions) and logically with connected fundamental processes. The literature review sections highlighted several recurrent questionings and discussions around the notion of function. We bear those reflections and we propose to go further in the particular context of a usage-driven innovation process of products and services, which is a much more specific design process than traditional 'routine' design generally considered in the mentioned studies (for example Galle explicitly restrict his discussion to the design of 'material artefacts' [10]).

For these reasons, we do not claim to propose an evolution of the general FBS model. This work is more a first attempt to adapt the FBS model in the particular context of usage-driven innovation. Kannengiesser and Gero [23] say that 'functionbehavior-structure (FBS) ontology and its derivative, the situated FBS framework, are domain-independent to describe designing processes'. We follow the same objective to propose a revised FBS model in Figure 3, which is domain-independent, to describe user-centered, and Usage-Driven Innovation Processes: the UDIP model. In particular, we explain in the next paragraphs how and why the first phases of this innovation process (frontend of innovation) are particularly impacted, to better reflect the cognitive process of RID innovators.

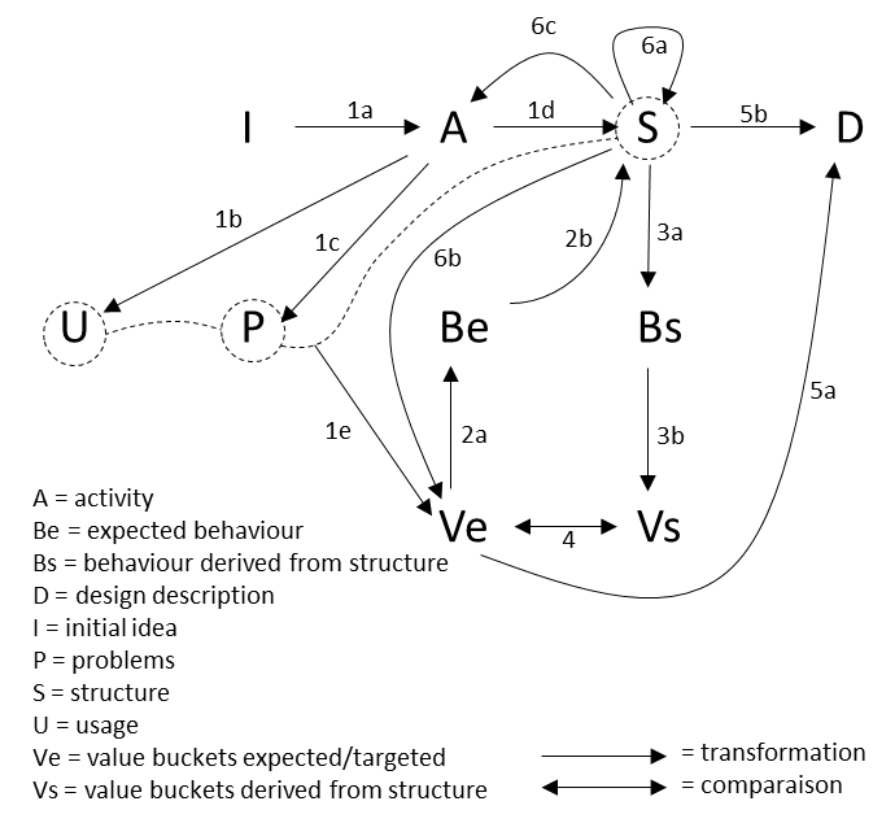

FIGURE 3. THE UDIP MODEL MADE OF 10 DESIGN ISSUES,
6 FUNDAMENTAL AND 15 ELEMENTARY PROCESSES

The proposed adaptation of the FBS model is also a descriptive model (describing existing artefacts) as a prescriptive model (prescript artefacts to design). We particularly illustrate the interconnections between descriptive and prescriptive issues and processes in Table 3, as these considerations are at the heart of the RID methodology.

The UDIP model differs notably from FBS model. In the following, we define and motivate the 10 design issues and six fundamental processes of the UDIP model, while highlighting evolutions from FBS model. We also illustrate our definitions with the example of innovating on a lamp for professionals and DIYers [19].

\section{The 10 design issues of UDIP model}

In FBS model [23], 'Requirements include all expressions of customer or market needs, demands, wishes and constraints 
that are explicitly provided to the designers at the outset of a design task. For example, requirement issues include "technical performance requirements [...] articulated by the customer" ([28], p. 150), "stakeholder requests" ([29], p. 166) and "customer needs and wants" '. In RID model, Requirements are banished for two reasons:

- It is illusory to think that customers or markets express needs and demands. Such requirements are, in practice, expressed (syntactically) by designers who try at best to synthesize many disparate data coming from customers and markets.

- Nothing is explicitly provided to the designers. In practice, it is a design process and cognitive task to observe user situations and fact and data from markets, interpret them and synthesize them into something (called afterwards 'Expected or targeted value buckets').

In the FBS model [21], Functions are designed constructs that represent 'the intended input/output relationship of a system' ([28], p. 31) or 'sequence of actions a system performs that yields an observable result of value to a particular actor' ([29], p 98).

In RID model, Functions are banished, as specifying a set of functions appears as too questionable to fulfil a given set of requirements. Choosing a specific set of sequence of actions instead of another, at an early design stage, is not a good grain size to express in a non-questionable manner what is expected in terms of service value. In RID, the focus is put on the service performances instead of the system sequence of actions; in other words, in RID the focus is put on the consequences of the sequence of actions of the system.

$R$ and $F$ are replaced by $I, A, U, P, V e$, standing for (initial) Idea, Activity (field), Usage, Problems, expected/targeted Value buckets. Objects are much different and at the same time require observation and modeling practices and know-how, while specifying at best the expected performances of services for users and presuming as few as possible the way to come up with solutions. Let us define in details these new design issues, and the adaptation of the others (Be, Bs, S and D).

Idea (initial) is the starting point of the innovating process. There must exist one (or a small set of) argument, motivation, or idea (of problem, new concept, new design principle, original structure...) to start designing from. In UDIP, this is important to record this initial idea, even if it only represents a portion of what FBS calls Requirements. In UDIP, it is believed that most of Requirements result from a primary investigation process (called Problem setting stage in RID) which is so determining that it must be considered as a part of the innovating/designing process.

Activity field represents a coherent set of existing activities or concerns of an identified class of users. This activity field represents a system boundary that is derived from the initial idea. Doing so, this activity filed becomes a much more legitimate territory to explore than to start from a questionable initial idea. The definition of this activity field may also be completed by the definition of an ideal goal, which is defined as the expectation of a successful and satisfactory activity from the viewpoint of the users.

Usage (situations) are archetypal scenarios lived by users of a certain kind (may be defined by socio-demographic peculiarities) in which some problems may occur. A usage situation may be more or less frequent in terms of repetitiveness and number of people concerned; one speaks of the size of a usage segment.

Problems (or pains) are failure modes with consequences of different severities. The severity and the probability of occurrence of a failure mode determine its importance. Therefore, they must be investigated to assess the potential of value creation for solving a given problem. Causes of failure modes as well must be investigated as they are major innovation seeds for removing or lowering failure modes.

Value buckets are frequent usage situations where important problems occur which are not well addressed by existing solutions (or structures $\mathrm{S}$ ). A value bucket is all the more important that no other existing solution brings satisfaction. For summary, the structure of a value bucket may be expressed by the logical expression of formula (1).

User $^{\wedge}$ Nowadays $^{\wedge}(P, U)^{\wedge} \overline{\text { SatisfactoryExistingSolution }}$

where $P=$ Problem (failure mode, causes, consequences, gravity, occurrence) and $U=U$ sageSituation (archetypal scenario lived by users, size)

Expected or targeted value buckets are the subset of important value buckets for which the innovation/design goal is to eradicate or lessen the problems. In RID, this subset is called the ambition perimeter (see Figure 1); in companies it is currently called the marketing brief.

Structure is made in UDIP of the detail design ProductService System (PSS) part and of the business model part. This latter part is not considered in FBS model, in the sense that previous studies about the FBS model never mentioned business considerations or business model as part of the structure of a design artefact.

Expected Behavior includes attributes that describe the PSS's expected interaction with the environment as well as the conceptual scenario of the business model.

Structure behavior (or "behavior derived from structure") includes those attributes of the PSS as well as of its business model that are measured, calculated or derived from the observation of a specific design solution and its interaction with the environment.

Value buckets derived from structure are pairs of problems and usages situations remaining for a proposed structure. A good design process must simulate with a good quality the expected performances and, conversely, the lack of problems under each typical usage situation (as done in papers $[3,15])$. There is a need to improve experimental Proofs of Concepts or to lead virtual simulations for the different usage situations. Here the UDIP model emphasizes the inherent segmentation of users and usage situations, whereas traditional 
design methods average in practice user types, expectations, usage contexts, and situations.

Design Documents comprise the documents considered in FBS model but also all relevant information gathered during the Problem setting stage, i.e. during the knowledge design subprocess of RID. However, this latter information is crucial to define properly expected value buckets Ve. In RID methodology, this information gathered during the knowledge design is synthesized into "books of knowledge" which are distinct from technical information defining the designed structure.

Once that we have described ten new or adapted design issues, the next subsection describes the associated fundamental processes.

\section{The six fundamental processes of UDIP model}

In RID, the six fundamental processes are the same than the ones of FBS model: Formulation, Synthesis, Analysis, Evaluation, Documentation, and Reformulation (expressed as three processes in FBS). However, it is made of 15 elementary design processes instead of nine for FBS model. These elementary processes are explained in Table 4 (next page) and numbered on Figure 3.

\section{An illustration of RID in the modified FBS framework}

We use the table format proposed by Cascini et al. [12] to present a case study where RID was applied in a project on smart lighting for DIY and manual work. The detailed case study can be found elsewhere [19]. The results are presented in Table 3. The students started from a wide brief: propose an intelligent lighting system for manual work, be it professional or amateur (DIY). They reframed this brief into a set of activity fields to be investigated. In these activity fields, they explored usage situations, problems experienced by users and existing solutions. They constructed typologies for these three dimensions. They then processed and synthesized this knowledge into a set of value buckets [3], i.e. serious problems happening in important usage situations where current market solutions provide poor relief (see Figure 4). This example illustrates the difficulty to represent real RID projects in the native FBS framework without losing details: all these activities happen even before the FBS notion of "requirements" are established.

\section{TABLE 3. ILLUSTRATION OF THE "FORMULATION" STAGE OF THE UDIP FRAMEWORK ON A CASE STUDY.}

\begin{tabular}{|c|c|c|}
\hline $\begin{array}{l}\text { Elementary } \\
\text { process }\end{array}$ & $\begin{array}{l}\text { From (example } \\
\text { variable) }\end{array}$ & To (example variable) \\
\hline $\mathrm{I} \rightarrow \mathrm{A}(\mathbf{1 a})$ & $\begin{array}{l}\text { Initial idea: } \\
\text { "Intelligent lighting } \\
\text { system at work" }\end{array}$ & $\begin{array}{l}12 \text { activity fields expressed as } \\
\text { professions and roles concerned } \\
\text { by the initial idea, e.g. dentists, } \\
\text { do-it-yourself-ers, plumbers, } \\
\text { electricians, mechanics, security } \\
\text { agent, etc. }\end{array}$ \\
\hline $\mathrm{A} \rightarrow \mathrm{U}(\mathbf{1 b})$ & $\begin{array}{l}\text { Activity fields } \\
\text { (professional and } \\
\text { DIY activities) }\end{array}$ & $\begin{array}{l}\text { List of usage situations, e.g. } \\
\text { moving about in a dark place or } \\
\text { precise inspection of an object }\end{array}$ \\
\hline$A \rightarrow P(1 c)$ & $\begin{array}{l}\text { Activity fields } \\
\text { (professional and } \\
\text { DIY activities) }\end{array}$ & $\begin{array}{l}\text { List of problems, e.g. shadow } \\
\text { casted by parts of the body or } \\
\text { movement restrictions and } \\
\text { physical pain }\end{array}$ \\
\hline$A \rightarrow S$ (1d) & $\begin{array}{l}\text { Activity fields } \\
\text { (professional and } \\
\text { DIY activities) }\end{array}$ & $\begin{array}{l}\text { List of solutions abstracted in a } \\
2 * 2 \text { framework of solution } \\
\text { principles: diffuse vs. directional } \\
\text { light and fixed vs. portable } \\
\text { systems }\end{array}$ \\
\hline $\begin{array}{l}\{\mathrm{U}, \mathrm{P}, \mathrm{S}\} \rightarrow \mathrm{Ve} \\
(\mathbf{1 e )}\end{array}$ & $\begin{array}{l}\text { Lists of usage } \\
\text { situations, problems } \\
\text { and existing } \\
\text { solutions }\end{array}$ & $\begin{array}{l}5 \text { value buckets to be addressed, } \\
\text { e.g. movement restriction while } \\
\text { manipulating an object in a dark } \\
\text { environment }\end{array}$ \\
\hline
\end{tabular}

\section{PROBLEMS}

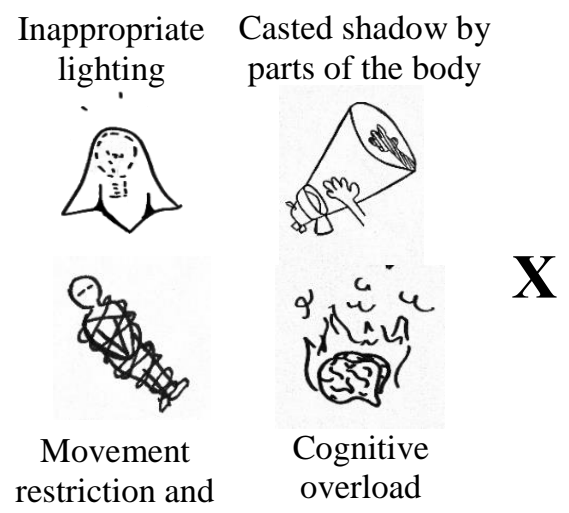

\section{USAGE SITUATIONS}

Moving in Precision inspection dark places of an object
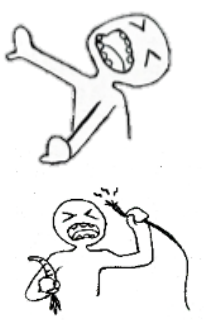

Manipulating an object in a dark place
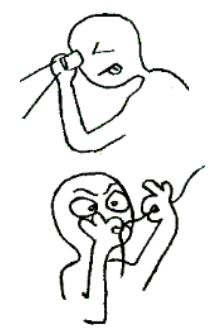

Precise manipulation of an object

\section{EXISTING SOLUTIONS}

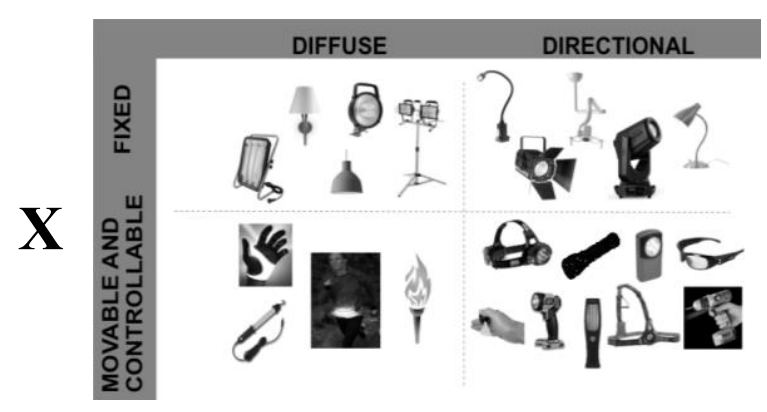
physical pain FIGURE 4. ILLUSTRATION OF VALUE BUCKETS IN THE SMART LIGHTING EXAMPLE: PROBLEMS HAPPENING IN USAGE
SITUATION WITH NO SATISFACTORY EXISTING SOLUTIONS 
TABLE 4. DESCRIPTION OF THE SIX FUNDAMENTAL DESIGN PROCESSES OF UDIP MODEL

\begin{tabular}{|c|c|}
\hline $\begin{array}{c}\text { Fundamental } \\
\text { processes }\end{array}$ & Elementary processes \\
\hline \multirow{5}{*}{ Formulation } & $\begin{array}{l}\text { Formulation 1a transforms (initial) idea into activity (field) (I } \rightarrow \text { A) } \\
\text { Starting from an initial idea, which may by anything like a problem, a technological or business solution, a design } \\
\text { principle..., this process consists in identifying an activity field made possibly of several sub-activities (see for } \\
\text { instance [19]). The objective of a RID design process is to allow the activity to be well done; this is the theory of } \\
\text { jobs-to-be-done of Christensen [16,30]. An ideal goal can also be expressed to formulate the innovative design } \\
\text { objective of "allowing the activity to be properly and satisfactorily done". This process is also called "problem } \\
\text { reframing". }\end{array}$ \\
\hline & $\begin{array}{l}\text { Formulation 1b transforms activity into usage }(\mathrm{A} \rightarrow \mathrm{U}) \text {. Inside the boundary of activity field, one must inventory } \\
\text { archetypical usage situations of a certain grain size in which users experiment problems of a certain type. Some } \\
\text { conditions to succeed this segmentation of usage situations are narrated in [15]. It is useful to represent graphically } \\
\text { usage situations thanks to storyboard or movie techniques, and to quantify all its attributes to get a reliable } \\
\text { representation of reality. This process is also called "usage investigation and modelling". }\end{array}$ \\
\hline & $\begin{array}{l}\text { Formulation 1c transforms activity into problems }(\mathrm{A} \rightarrow \mathrm{P}) \text {. This process is also called "problems investigation } \\
\text { and modelling". }\end{array}$ \\
\hline & $\begin{array}{l}\text { Formulation 1d transforms activity field into existing structures (solutions) }(\mathrm{A} \rightarrow \mathrm{S}) \text {. This process is also called } \\
\text { "Investigation of existing solutions". Here } \mathrm{S} \text { represent archetypes of existing solution structures and not the } \\
\text { designed structure. This set of existing structures (solutions) must serve to assess if a value bucket is important. }\end{array}$ \\
\hline & $\begin{array}{l}\text { Formulation 1e transforms usage, problems and existing structures (solutions) into expected value buckets }(\{U, P, \\
S\} \rightarrow \text { Ve). This elementary process is represented by the DSM-Value-Bucket algorithm in the RID methodology } \\
(\text { see }[3]) \text {. }\end{array}$ \\
\hline \multirow{2}{*}{ Synthesis } & $\begin{array}{l}\text { Synthesis } 2 \text { a transforms expected value buckets into expected behavior ( } \mathrm{Ve} \rightarrow \mathrm{Be}) \text {. This process is also called "PSS } \\
\text { scenario and business model scenario ideation". }\end{array}$ \\
\hline & $\begin{array}{l}\text { Synthesis } 2 \mathbf{b} \text { transforms expected behavior into structure }(\mathrm{Be} \rightarrow \mathrm{S}) \text {. This process is also called "PSS and business } \\
\text { model conceptual design" }\end{array}$ \\
\hline \multirow[b]{2}{*}{ Analysis } & $\begin{array}{l}\text { Analysis 3a transforms structure into behavior derived from structure ( } \rightarrow \text { Bs). This process is also called } \\
\text { "Simulation, prototyping and validation". }\end{array}$ \\
\hline & $\begin{array}{l}\text { Analysis } \mathbf{3 b} \text { transforms behavior derived from structure into value buckets derived from structure }(\mathrm{Bs} \rightarrow \mathrm{Vs}) \text {. This } \\
\text { process consists in observing that the behavior derived from structure effectively remove or alleviate problems in } \\
\text { given usage situations. }\end{array}$ \\
\hline Evaluation & $\begin{array}{l}\text { Evaluation compares expected value buckets with value buckets derived from structure (Ve } \leftrightarrow \text { Vs). Here, the } \\
\text { comparison is made between expected and derived-from-structure value buckets. In UDIP, this is the result that } \\
\text { matters, i.e. Vs being close to Ve, and not the means for the structure to act, i.e. Bs being close to Be. }\end{array}$ \\
\hline \multirow[t]{2}{*}{ Documentation } & $\begin{array}{l}\text { Documentation 5a transforms expected value buckets into documentation (Ve } \rightarrow \text { D). This documentation is the } \\
\text { one generated during the Problem setting stage, especially during the knowledge design sub-process of RID. It is } \\
\text { not mentioned in the initial FBS model. However, we believe that this information (synthesized into "books of } \\
\text { knowledge" in RID) must be carefully saved since: (a) value buckets of Ve types are gold nuggets and their fine } \\
\text { description is invaluable, (b) only some value buckets will be selected in the ambition perimeter for following up } \\
\text { with the ideation phase, then recording the others can serve in the future, (c) keeping the reasoning traceability } \\
\text { leading to value buckets of Ve types is determining for a posteriori justifying the usefulness of the structure solution. }\end{array}$ \\
\hline & $\begin{array}{l}\text { Documentation } \mathbf{5 b} \text { transforms structure into documentation }(\mathrm{S} \rightarrow \mathrm{D}) \text {. This process corresponds to the traditional } \\
\text { technical documentation about the solution structure. }\end{array}$ \\
\hline \multirow{3}{*}{ Reformulation } & Reformulation 6a transforms structure into new structure $\left(S \rightarrow S^{\prime}\right)$. Another solution structure is tested. \\
\hline & $\begin{array}{l}\text { Reformulation } \mathbf{6 b} \text { transforms structure into new expected value buckets }(\mathrm{S} \rightarrow \mathrm{Ve} \text { '). Another subset of value buckets } \\
\text { (ambition perimeter) is decided. }\end{array}$ \\
\hline & Reformulation 6c transforms structure into new activity $\left(\mathrm{S} \rightarrow \mathrm{A}^{\prime}\right)$. Another activity field is tested. \\
\hline
\end{tabular}




\section{DISCUSSION}

We have proposed an evolution of the FBS framework to better encompass the specificities of usage-driven innovation processes like RID methodology. Although UDIP model seems to bring more complexity to the initial FBS model of designing, we believe that while generic models are important, it is also useful to develop models that can address specific issues in design. The 'fuzzy front end' of innovation is not wellunderstood, and we may need detailed models at first, before we can extract the main properties and possibly revert to simpler models.

This work is a first attempt to adapt the FBS model of designing. The evolutions mainly concern the (chronologically) first design issues of the original FBS framework, but by replacing Requirements and Functions by new issues, it also affects most of the fundamental processes.

For summary, the main evolutions of the FBS framework, proposed in the UDIP model are:

1. $\mathrm{R}$ (requirements) and $\mathrm{F}$ (functions) are banished from RID for being too artificial and interpretable by designers. They are too far from an objective, factual expression.

2. I (initial idea), A (activity field), U (usage), $P$ (problems), Ve (expected/targeted value buckets) and Vs (value buckets derived from structure) are introduced to enrich the traditional "task clarification" to come up with a more objective, quantifiable and factual prioritized list of value buckets and, further ambition perimeter.

3. I is much different from R: on the one hand, I only represents a portion of what FBS calls Requirements. On the other hand, in UDIP, Requirements result from a primary investigation process starting with this initial idea.

4. The comparison is not anymore between $\mathrm{Be}$ and $\mathrm{Bs}$, but between Ve and Vs. It means that, in RID, we do not care about a prescribed behavior, we instead focus on the ability of the behavior derived from the structure to alleviate or totally remove the problems encountered by users in an activity (for a perfect "jobs-to-be-done"). This approach is more oriented on the service delivery performances and overall quality than on the way the service is delivered. RID is more adapted to the design of PSS (Product-Service Systems).

5. Elementary process $1 \mathrm{~d}$ is novel. It means that RID pay more attention to existing structures in the competitive landscape (called "existing solutions" in RID) for specifying design objectives (Ve) than the traditional designing methods.

6. Elementary process $5 \mathrm{a}$ is novel. It means that RID attaches as much importance to generate documentation during problem setting as to documentation during problem solving. RID is more compatible with open innovation principles for which different types of deliverables may generate value along an innovation funnel like licensing [31, 32].
A fine analysis of this work highlights the fact that in the RID methodology (and thus in the UDIP model), behaviors are considered (chronologically) before functions. In the Solution Design phase of RID (after the identification of value buckets), first one or several ambitioned usage scenarios are identified (associated with expected behaviors in FBS), then functions to fulfill these behaviors are derived.

This work being a first attempt to adapt the FBS framework, several limits need to be mentioned. First, the case study proposed in the paper is only partial, as it only illustrates the Formulation process of the UDIP model. One perspective is to extend this case study to cover the entire UDIP model. Other case studies should also be considered to question the UDIP model, eventually to amend it, and finally to move towards a true validation.

Second, we only consider in this paper the 'classical' FBS model of designing. We mentioned in the literature review the discussion and evolutions of the model, and in particular the situated FBS model ( $\mathrm{sFBS}$ ) and the evolutions of the sFBS proposed by Cascini et al. [12]. The main perspective of this work is thus to extend the UDIP model in the three situated worlds and to discuss Cascini's proposals about the notion of requirements and functions. This will be a natural extension of this study.

\section{CONCLUSION}

This study aims at exploring how our understanding of the Radical Innovation Design (RID) methodology can be enhanced by confronting the methodology with existing formal frameworks of design reasoning and of design process. We propose to use the FBS (Function-Behavior-Structure) model of designing proposed by John Gero as a recognized (but also challenged) conceptual framework in the literature. A literature review shows in-depth discussions in particular concerning the notions of Requirements and Functions that are questioned and even enriched by some authors.

By projecting the RID process in the FBS framework, those two design issues in particular do not fit with the RID principles on the one hand, but also with the reality of cognitive processes observed from dozens of RID projects in the past years. We come up with an evolution of the FBS model, called UDIP (standing for Usage-Driven Innovation Process) model, where requirements and functions are replaced by new design issues called initial idea, activity field, usage, problems, expected value buckets and value buckets derived from structure. The introduction of these new issues leads to the adaptation or introduction of (new) fundamental design processes. The UDIP model does not ambition to replace the pre-existing FBS model. It is more a first proposal to adapt this model in the particular context of usage-driven innovation methodologies, where the notion of function become questionable.

The UDIP model is partially illustrated in this paper with a student project on the development of an innovative solution for smart lighting. Further works will focus on going further in the application and validation of this model, as well as the extension 
of the UDIP model to consider the situated FBS model and its evolutions.

\section{REFERENCES}

[1] Gericke, K., Eckert, C. M., and Stacey, M., "What do we need to say about a design method?," Proc. ICED 2017, The Design Society, Vancouver, BC, Canada.

[2] Lipsey, M. W., 1993, "Theory as method: Small theories of treatments," New Directions for Program Evaluation, 1993(57), pp. 5-38.

[3] Yannou, B., Cluzel, F., and Farel, R., 2016, "Capturing the relevant problems leading to pain- and usage-driven innovations: The Dependency Structure Modeling Value Bucket algorithm," Concurrent Engineering Research and Applications, (online first).

[4] Yannou, B., Jankovic, M., Leroy, Y., and Okudan Kremer, G. E. O., 2013, "Observations From Radical Innovation Projects Considering the Company Context," Journal of Mechanical Design, 135(2), pp. 021005-021017.

[5] Yannou, B., "Supporting need seeker innovation: the Radical Innovation Design methodology," Proc. International Conference on Engineering Design (ICED'15), The Design Society, Milano, Italy, pp. 51-60.

[6] Lamé, G., Yannou, B., and Cluzel, F., 2018, "Usage-driven problem design for radical innovation in healthcare," BMJ Innovations, 4(1), pp. 15-23.

[7] Kroll, E., and Koskela, L., 2016, "Explicating concepts in reasoning from function to form by two-step innovative abductions," Artificial Intelligence for Engineering Design, Analysis and Manufacturing, 30(2), pp. 125-137.

[8] Lamé, G., Yannou, B., and Cluzel, F., 2018, "Analyzing RID methodology through the lens of innovative abduction," DESIGN 2018, The Design Society, Dubrovnik, Croatia.

[9] Gero, J. S., 1990, "Design prototypes. A knowledge representation schema for design," AI Magazine, 11(4), pp. 2636.

[10] Galle, P., 2009, "The ontology of Gero's FBS model of designing," Design Studies, 30(4), pp. 321-339.

[11] Gero, J. S., and Kannengiesser, U., 2004, "The situated function-behaviour-structure framework," Design Studies, 25(4), pp. 373-391.

[12] Cascini, G., Fantoni, G., and Montagna, F., 2013, "Situating needs and requirements in the FBS framework," Design Studies, 34(5), pp. 636-662.

[13] Vermaas, P. E., and Dorst, K., 2007, "On the conceptual framework of John Gero's FBS-model and the prescriptive aims of design methodology," Design Studies, 28(2), pp. 133-157.

[14] Yannou, B., Wang, J., Rianantsoa, N., Hoyle, C., Drayer, M., Chen, W., Alizon, F., and Mathieu, J.-P., 2009, "Usage Coverage Model for Choice Modeling: Principles," (49026), pp. 407-418.

[15] Bekhradi, A., Yannou, B., Farel, R., Zimmer, B., and Chandra, J., 2015, "Usefulness Simulation of Design Concepts," Journal of Mechanical Design, 137(7), p. 071412.

[16] Christensen, C. M., Hall, T., Dillon, K., and Duncan, D. S., 2016, "Know your customers" "jobs to be done"," Harvard Business Review, 9, pp. 54-62.
[17] Kim, W. C., and Mauborgne, R., 2015, Blue ocean strategy: how to create uncontested market space and make the competition irrelevant, Harvard Business Review Press, Boston, MA.

[18] Jaruzelski, B., Staack, V., and Goehle, B., 2014, "Proven paths to innovation success," Strategy+ Business, Booz\&Company.

[19] Bekhradi, A., Yannou, B., Cluzel, F., and Vallette, T., "Categorizing user pains, usage situations and existing solutions in front end of innovation: The case of smart lighting project," Proc. International Conference on Engineering Design (ICED'17), The Design Society, Vancouver, BC, Canada.

[20] Lamé, G., Yannou, B., and Cluzel, F., in press, "Usagedriven problem design for radical innovation in healthcare," BMJ Innovations.

[21] Osterwalder, A., and Pigneur, Y., 2010, Business model generation: a handbook for visionaries, game changers, and challengers, Wiley, Hoboken, NJ.

[22] Yannou, B., Farel, R., Cluzel, F., Bekhradi, A., and Zimmer, B., 2016, "The UNPC innovativeness set of indicators for idea or project selection and maturation in healthcare," International Journal of Design Creativity and Innovation, pp. 1-17.

[23] Kannengiesser, U., and Gero, J. S., 2015, "Is designing independent of domain? Comparing models of engineering, software and service design," Research in Engineering Design, 26(3), pp. 253-275.

[24] Gero, J. S., Jiang, H., and Williams, C. B., 2013, "Design cognition differences when using unstructured, partially structured, and structured concept generation creativity techniques," International Journal of Design Creativity and Innovation, 1(4), pp. 196-214.

[25] Pourmohamadi, M., and Gero, J. S., "LINKOgrapher: an analysis tool to study design protocols based on FBS coding scheme," Proc. ICED2011, The Design Society.

[26] Lammi, M. D., 2011, "Characterizing high school students' systems thinking in engineering design through the functionbehavior-structure (FBS) framework," Utah State University.

[27] Russo, D., and Spreafico, C., 2015, "TRIZ 40 Inventive Principles Classification through FBS Ontology," Procedia Engineering, 131, pp. 737-746.

[28] Pahl, G., Beitz, W., Feldhusen, J., and Grote, K.-H., 2007, Engineering Design, Springer-Verlag London, London.

[29] Kruchten, P., 2004, The rational unified process : an introduction, Addison-Wesley, Boston.

[30] Christensen, C. M., and Raynor, M. E., 2003, The innovator's solution: creating and sustaining successful growth, Harvard Business School Press, Boston.

[31] Chesbrough, H. W., 2003, Open innovation : the new imperative for creating and profiting from technology, Harvard Business School ; Maidenhead : McGraw-Hill, Boston, Mass.

[32] Chesbrough, H. W., Vanhaverbeke, W., and West, J., 2006, Open innovation : researching a new paradigm, Oxford University Press, Oxford. 